\title{
Infliximab can reduce mortality from 35 to $14 \%$ in critically ill patients with COVID-19: perhaps some potential confounders to consider
}

\author{
Patrick M. Honore*, Leonel Barreto Gutierrez, Luc Kugener, Sebastien Redant, Rachid Attou, Andrea Gallerani and \\ David De Bels
}

We read with great interest the recent article by Stallmach et al. who reported data from a small retrospective case series of patients with COVID-19 that received infliximab compared to a contemporaneous cohort that received supportive care alone [1]. Infliximab (anti-TNF) was used to target proinflammatory cytokines that are associated with deterioration of organ function and poor outcomes in patients with COVID-19 [1, 2]. The authors reported that mortality was reduced from $35 \%$ in the control group to $14 \%$ in the infliximab group [1]. We would like to make some comments. Looking at the baseline characteristics of the patients, we can see that ferritin levels in the infliximab group were almost double those in the control group (2777.4 vs $1453 \mu \mathrm{g} / \mathrm{L})$ [1]. It is possible that the patients in the treated group may have had secondary hemophagocytic lymphohistiocytosis (sHLH) syndrome induced by SARS-CoV-2 [3]. The HScore, one of the tools to diagnose HLH, assigns no points to a ferritin below $2000 \mu \mathrm{g} / \mathrm{L}$, while a ferritin between 2000 and $6000 \mu \mathrm{g} / \mathrm{L}$ adds 35 points, showing that the limit of
$2000 \mu \mathrm{g} / \mathrm{L}$ is really crucial [3]. Due to the massive cytokine release seen in patients with the condition, HLH is considered to be a cytokine storm syndrome [3]. In potential sHLH, early use of high-dose steroids alone can be successful, consistent with the recent findings regarding the efficacy of dexamethasone in patients with severe COVID-19 receiving any form of respiratory support [4]. Other drugs such as infliximab may be life-saving in this group of patients. In conclusion, on the basis of the difference in ferritin levels between the two groups and the potential diagnosis of sHLH, the two groups in this study are not well matched [3]. A diagnosis of sHLH could explain the enormous cytokine storm responding so well to infliximab [1] and may also explain why dexamethasone is so effective in patients with severe COVID-19 [4]. The sHLHcytokine storm may be the main reason for the rapid deterioration seen in patients with COVID-19 [3]. It is advisable to measure baseline ferritin before starting any immunological treatment in order to improve the efficacy [5]. 
Authors' response

Andreas Stallmach', Andreas Kortgen², Falk Gonnert ${ }^{3}$, Sina M. Coldewey ${ }^{2,4,5}$, Philipp Reuken ${ }^{1}$ and Michael Bauer ${ }^{2,5}$

'Department of Internal Medicine IV (Gastroenterology, Hepatology, and Infectious Diseases), Jena University Hospital, Jena, Germany

${ }^{2}$ Department of Anesthesiology and Intensive Care Medicine, Jena University Hospital, Jena, Germany

${ }^{3}$ Department of Anesthesiology and Intensive Care Medicine, SRH Wald-Klinikum Gera, Gera, Germany

${ }^{4}$ Septomics Research Center, Jena University Hospital, Jena, Germany

${ }^{5}$ Center for Sepsis Control and Care, Jena University Hospital, Jena, Germany

To the editor:

We thank Dr. Honore and colleagues for their thoughtful comments pointing towards a potential secondary hemophagocytic lymphohistocytosis (sHLH) characterized by pancytopenia, hyper-coagulation, acute kidney injury, and hepatobiliary dysfunction associated with COVID-19. Based on their suggestion, we applied the hemophagocytosis score (HScore) and obtained a median Hscore of 171 (136;186) for IFX-treated patients and $136(77 ; 182)$ for controls $(p=$ 0.393) reflecting that some but not all of the patients fulfilled the HScore criterium of sHLH, i.e., a score above 169. Nevertheless, all of the patients displayed a profound inflammatory state in particular in the IFX-treated patients, reflecting the experimental therapeutic approach. A recent proposal by a panel of experts suggested to screen all patients with severe COVID-19 both for a hyperinflammatory state using laboratory tests (e.g., ferritin, decreased platelet count or erythrocyte sedimentation rate) and for the HScore to identify the subgroup of patients for whom immunosuppressive therapies (e.g., infliximab or anakinra [6]) could improve outcome [7]. Whether severe COVID-19 indeed reflects a form of sHLH is still a matter of controversy; however, the evidence to support antiinflammatory interventions in the most severe cases is meanwhile supported by prospective randomized evidence for dexamethasone [4]. Though, research addressing the optimum immune modulating drug, e.g., depending on the severity of the cytokine response, is warranted [8].

\section{Abbreviations}

TNF: Tumor necrosis factor; IL-6: Interleukin-6; sHLH: Secondary hemophagocytic lymphohistiocytosis; HS: Hematophagocytic syndrome score

\section{Acknowledgements}

None.

\section{Authors' contributions}

$\mathrm{PMH}, \mathrm{SR}$, and DDB designed the paper. All authors participated in drafting and reviewing. The authors read and approved the final version of the manuscript.
Availability of data and materials

Not applicable.

Ethics approval and consent to participate

Not applicable.

\section{Consent for publication}

Not applicable.

\section{Competing interests}

The authors declare to have no competing interests.

Received: 29 August 2020 Accepted: 15 September 2020

Published online: 09 October 2020

References

1. Stallmach A, Kortgen A, Gonnert F, Coldewey SM, Reuken P, Bauer M. Infliximab against severe COVID-19-induced cytokine storm syndrome with organ failure-a cautionary case series. Crit Care. 2020;24(1):444. https://doi. org/10.1186/s13054-020-03158-0.

2. Liu J, Li S, Liu J, Liang B, Wang X, Wang H, et al. Longitudinal characteristics of lymphocyte responses and cytokine profiles in the peripheral blood of SARS-CoV-2 infected patients. EBioMedicine. 2020;55:102763. https:/doi.org/ 10.1016/j.ebiom.2020.102763.

3. Soy M, Atagündüz P, Atagündüz I, Sucak GT. Hemophagocytic lymphohistiocytosis: a review inspired by the COVID-19 pandemic. Rheumatol Int. 2020:1-12. https://doi.org/10.1007/s00296-020-04636-y.

4. The RECOVERY Collaborative Group. Dexamethasone in hospitalized patients with COVID-19 - preliminary report. N Engl J Med. 2020. https://doi. org/10.1056/NEJMoa2021436.

5. Grangé S, Buchonnet G, Besnier E, Artaud-Macari E, Beduneau G, Carpentier $D$, et al. The use of ferritin to identify critically ill patients with secondary hemophagocytic lymphohistiocytosis. Crit Care Med. 2016;44(11):e1045-53. https://doi.org/10.1097/CCM.0000000000001878.

6. George Dimopoulos et al. Favorable anakinra responses in severe COVID-19 patients with secondary hemophagocytic lymphohistiocytosis. Cell Host Microbe 2020;28(1):117-123.e1. doi: https://doi.org/10.1016/j.chom.2020.05. 007. Epub 2020 May 14.

7. Mehta P, McAuley DF, Brown M, et al. COVID-19: consider cytokine storm syndromes and immunosuppression. Lancet. 2020;395(10229):1033-4 https://doi.org/10.1016/S0140-6736(20)30628-0.

8. Shrestha GS, Paneru HR, Vincent J. Precision medicine for COVID-19: a call for better clinical trials. Crit Care. 2020;24:282 https://doi.org/10.1186/s13054020-03002-5.

\section{Publisher's Note}

Springer Nature remains neutral with regard to jurisdictional claims in published maps and institutional affiliations. 